\title{
RELATION BETWEEN LEAN BUNDLES AND AGE OF THE PLANT: A CASE STUDY ON CENTRAL INDIA MANUFACTURING INDUSTRIES
}

\section{YASH DAVE}

Selection Grade Lecturer, Dhar Polytechnic College, Dhar, Madhya Pradesh, 454001, India

Received: Jun 08, 2020; Accepted: Jun 28, 2020; Published: Sep 09, 2020; Paper Id.: IJMPERDAUG202024

\section{INTRODUCTION}

Womack \& Jones (2010) identified five basic principles of lean namely; specify value, Identify the value stream, establish the flow, respond to customer pull and finally pursue perfection. The main emphasis of these five principles is to eliminate the Muda (waste) but this can only be possible when these principles will be applied and adopted as work culture as well as by inculcating the habit of continuous improvement among employees rather than having a rigid control system. The main idea and logic behind the lean principles is that to make understand that every organization has its own way to use the lean practices as per the requirement in order to eliminate the waste. Lean principles shows that lean manufacturing is not only limited to implementation of lean practices technically but it also involves some critical factors such as age of the plant. It is predominant that age of the plant is one of the important aspects in order to use the lean practices and provide the platform to study the effect of age of the plant on the implementation of lean practices in the industries. In this research study researcher has characterized and coded the number of years established (plant of the age) in research instrument in to four categories such as 1 for plant setup within 5 years, 2 for plants having the age of the plant between five to ten years, 3 for plants having the age of the plant between eleven to twenty years, and 4 for plants having the age of the plant more than twenty years. In this research study, the age of the plant aspect has been considered and its relation with the implementation of lean practices has also been studied.

\section{LITERATURE REVIEW}

Jadhav et al. (2015) concluded that many lean tools can be adapted for organization needs and there is a need to provide guidance on how to choose tools and increase the accessibility. Kumar \& Kumar (2016) endorsed that successful implementation of lean manufacturing can be ensured by knowing the lean manufacturing elements and their level and indicated that companies must focus on engaging their employee's to work for continuous improvement and wastage identification so that lean implementation can be made easy in the Indian industry and ultimately Indian industry should identify the priority of the area for improvement in order to enhance the impact of 
elements in lean manufacturing and consequently improve upon their competitiveness. Balaji \& Muniraju (2017) discussed all the major challenges faced in implementation of lean in Indian MSMEs. Priya \& Saleeshya (2018) presented a case study of an Indian pharmaceutical firm to outline the scope of a successful lean based manufacturing strategy implementation. Ramakrishnan et al. (2019) showed that how Lean Manufacturing techniques are being implemented in Indian SMEs widely. They also outlined the role of Government of India. Panizzolo (1998) divided the lean practices into six areas which are Process and equipment, Manufacturing, Planning and control human resources, product design, Supplier relationship, and Customer relationship. Shah \& Ward (2003) grouped the lean practices in four groups named as bundles. Each bundle (group) consists of various lean manufacturing practices. These four bundles are JIT, TQM, TPM and HRM. They have concluded in their study that these four bundles have positive effect on the operational performance. In these all four bundles, each bundle is having a different background or roots. Review of literature shows that lean bundles have to be considered as a system as suggested by Shah \& Ward, (2007).Dal Pont et al. (2008) identify three bundles; namely JIT (with items such as JIT delivery, frequent supplier delivery, Kanban pull systems, small lot sizes etc.), TQM (with items like statistical process control, Poka yoke, equipment problem solving, etc) and HRM (with items such as employee encouragement, multiple task training, flat organization structure, etc). Lyonnet (2010) grouped twenty lean manufacturing practices that are frequently mentioned in literatures and categorized them into six bundles associated with Just-in-time, Continuous improvement, Quality, Elimination of waste, People management, and Visual management). By reviewing the literature on specifically lean bundles most of the researchers have supported the grouping of lean manufacturing in to four major areas which are Just-in-time (JIT), Total productive maintenance (TPM), Total quality management (TQM), Human resource management (HRM).In this way, this research study has been carried out by grouping the twenty five lean practices in to these four lean bundles (groups).In continuation of this, literature has also been reviewed bundle wise.

\section{JIT Bundle}

JIT bundle consists of all the lean manufacturing practices related with flow such as lot size reduction, cycle time reduction, and quick change over techniques, Kanban etc. Fullerton \& McWatters (2001) showed that implementing quality, continuous improvement and waste reduction practices enhance the firm competitiveness. In India, companies like Maruti Udyog Limited (MUL), Eicher, Escorts, Telco, Tisco, TVS, etc., have adopted JIT-based systems and improved their product quality [20].

\section{TQM Bundle}

This bundle involves all the lean practices which is associated with the improvement in quality. TQM is an integrated component of lean philosophy and consists of group of practices that primarily focused on involvement of management, workers, suppliers, and customers, in order to meet or exceed customer expectations. Ul Hassan et al. (2012) alleged that with TQM practices, manufacturing organizations are more likely to achieve better performance in customer satisfaction, employee relations, quality and business performance than without TQM practices.

\section{TPM Bundle}

In the highly competitive environment, to be successful and to achieve world-class-manufacturing, organizations must possess both efficient maintenance and effective manufacturing strategies. The effective integration of maintenance function with engineering and other manufacturing functions in the organization can help to save huge amounts of time, 
money and other useful resources in dealing with reliability, availability, maintainability and performance issues [11].Originally introduced as a set of practices and methodologies focused on manufacturing equipment performance improvement. TPM is an innovative approach to maintenance that optimizes equipment effectiveness, removes breakdowns, and promotes autonomous maintenance by operators through day-to-day activities involving total workforce [2].

\section{HRM Bundle: Shah \& Ward (2003)}

Affirmed that the HRM bundle has significant theoretical and empirical support. The most commonly cited HRM practices are employee's involvement, multi-skilled workforce, multi-functional work teams, education and training. HRM is a set of practices that favor work flexibility and personnel communication thus avoiding traditional hurdles that impede innovation and continuous improvement [3, 17]. Lean production should be considered as a human system. Journey towards lean enterprise commences with proper human resource management. Human resource management (HRM) practices add value and helps in identifying value stream of the business [6].

\section{Number of Years of Establishment (Age of the Plant)}

The age of the plant is an influential factor for lean practices implementation across the plant in rightful manner. As the past literature suggest that the more the age of the plant is, the more problems associated with the implementation of lean practices such as, cycle time reduction, JIT, value stream mapping and other practices also. Age of the plant may imply a tendency toward resistance to change, since organizations develop a set of organizational routines or practices over a period of time and the longer the organization has experience with the practices, the harder it is to change or replace them [16]. Older plants usually have such a work culture which supports the old pattern and habits related with working in an organization or industry and generally not supportive to the new innovative practices such as lean practices. Shah \& Ward (2003) identified 22 lean practices, classified these practices into four main categories: just-in-time, total productive maintenance, total quality management, and human resource management and examined the influence of plant size, plant age, and unionization on implementation of these practices. Results showed strong support for the influence of plant size on lean implementation, whereas the influence of unionization and plant age was less pervasive and concluded that older plants are less likely to implement lean manufacturing practices than newer plants. As suggested by Siemerink (2014), the tendency to exploit or explore the organizational innovations is also affected by an organization's history captured by its age, size, slack resources, absorptive capacity, organizational structure, and culture. As reported by Tortorella et al.(2015), that older plants tend to present problems denotes an obstacle for double loop learning, specifically at a team level, which emphasizes the importance of adopting management practices that minimize such kind of problem.

\section{OBJECTIVE}

A research question is a more suitable way in designing the research project framework as compare to other methods of addressing the research problem. This study addressed following objective related to application level of lean practices and its relation with important aspect i.e. age of the plant. In this way the objective of this research paper is "To study the relation between practical use of the lean practices in the industries and age of the plant". 


\section{RESEARCH METHODOLOGY}

In this research study, for collecting the primary data a dedicated questionnaire has been prepared and used for data collection. The main method of data collection for the survey strategy is the questionnaire. The questionnaire was developed in line with the theoretical framework and factors identified in the literature review and described in the form of statements or questions. The next step of instrument (questionnaire) development was item construction. Section A section was designed to get the general information about the organization, Section B was designed to gather information about the level of awareness and the use of lean practices in the organization. The making of questionnaires includes the listing of questions leading to provide the answers to the research question. All the questions were close ended and this ensures that responses would be valid. To reflect the purpose of this instrument, a Likert-type scale is used. When using a Likert-type scale, the responses are numerical, and the respondents make an evaluation of the statement based on magnitude [8]. For sections B the scale was as follows: strongly disagree (1), disagree (2), neutral (3), agree (4) and strongly agree (5); Content validity and discriminant validity has been checked and established during the analysis of the data. The ranges of observation for this study were sampled from central India manufacturing industries, which included automotive, steel, motor, forging and casting. The questionnaires were distributed to 250 industries located across the central India and 128 usable questionnaires were returned. This constituted a response rate of $51 \%$ which is well accepted in literature. To study the relation between practical use of the lean practices in the industries and age of the plant (No. of years of establishment) have been done by using the one way anova tool through SPSS software version 20.The data collected from the respondents were coded and entered into the MS excel software program and then moved into SPSS software (statistical package for social sciences) for detailed analysis.

\section{ANALYSIS}

In this research study, descriptive and inferential statistics both are applied. Descriptive statistics are simply explaining what data is or what data show. Inferential statistics is about reaching conclusion that extends beyond the present data. In this way the data which was collected by means of questionnaires is analyzed and the findings are presented with the help of statistical software. Industries are analyzed as per the total number of years of establishment (age of the plant). Industries established more than 20 years are accounted to $36 \%$ and industries which are established less than 20 years but more than 10 years are accounted for 26\%. Industries which are established less than 10 years but more than 5 years are accounted to $29 \%$. At the last industries which are established less than 5 years are accounted to mere $9 \%$, as shown in figure 1.

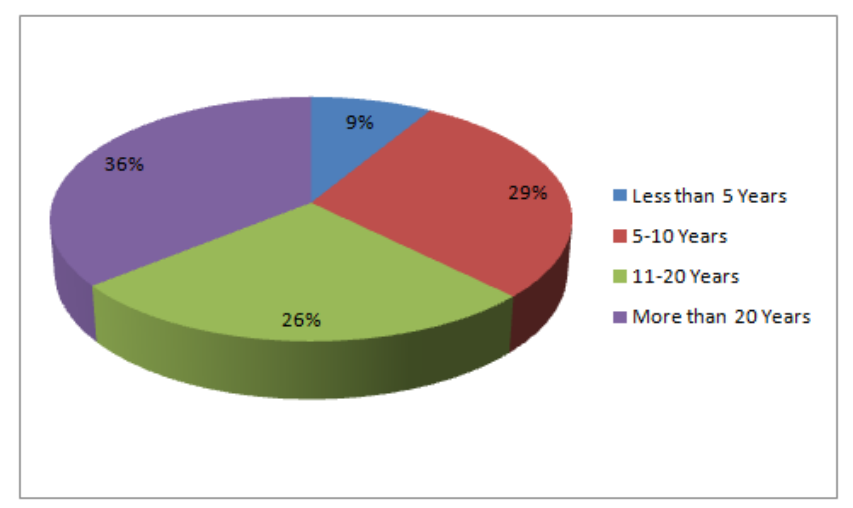

Figure 1: Years of Establishment. 
Relationship between lean bundles and number of years of establishment: In this research study, the relationship between lean bundles and number of years of establishment has been investigated through one way anova. The anova table is presented in table 1.

Table 1: One Way ANOVA (Number of Years of Establishment)

\begin{tabular}{|c|l|c|c|c|c|c|}
\hline \multicolumn{2}{|c|}{} & Sum of Squares & df & Mean Square & F & Sig. \\
\hline \multirow{3}{*}{ IIT } & Between Groups & 3.713 & 3 & 1.238 & .304 & .823 \\
\cline { 2 - 8 } & Within Groups & 505.256 & 124 & 4.075 & & \\
\cline { 2 - 8 } & Total & 508.969 & 127 & & & \\
\hline \multirow{3}{*}{ TPM } & Between Groups & 38.970 & 3 & 12.990 & 6.128 .001 \\
\cline { 2 - 9 } & Within Groups & 262.835 & 124 & 2.120 & & \\
\cline { 2 - 9 } & Total & 301.805 & 127 & & & \\
\hline \multirow{4}{*}{ TQM } & Between Groups & 8.653 & 3 & 2.884 & 1.803 & .150 \\
\hline & Within Groups & 198.339 & 124 & 1.600 & & \\
\cline { 2 - 9 } & Total & 206.992 & 127 & & & \\
\hline \multirow{3}{*}{ HRM } & Between Groups & 46.610 & 3 & 15.537 & 1.320 .271 \\
\cline { 2 - 9 } & Within Groups & 1459.265 & 124 & 11.768 & & \\
\cline { 2 - 9 } & Total & 1505.875 & 127 & & & \\
\hline
\end{tabular}

The results of one way anova as shown in table 1 depicts that the number of years of establishment significantly influences TPM Only $(\mathrm{F}(3,124)=6.12, \mathrm{p}<.01)$, Number of years of establishment has no influences on HRM $(\mathrm{F}(3,124)$ $=1.3, \mathrm{p}=.271)$, JIT $(\mathrm{F}(3,124)=.304, \mathrm{p}=.823)$ and TQM $(\mathrm{F}(3,124)=1.803, \mathrm{p}=.150)$. The trends of this effect have been shown with mean plot as shown in figure 2 .

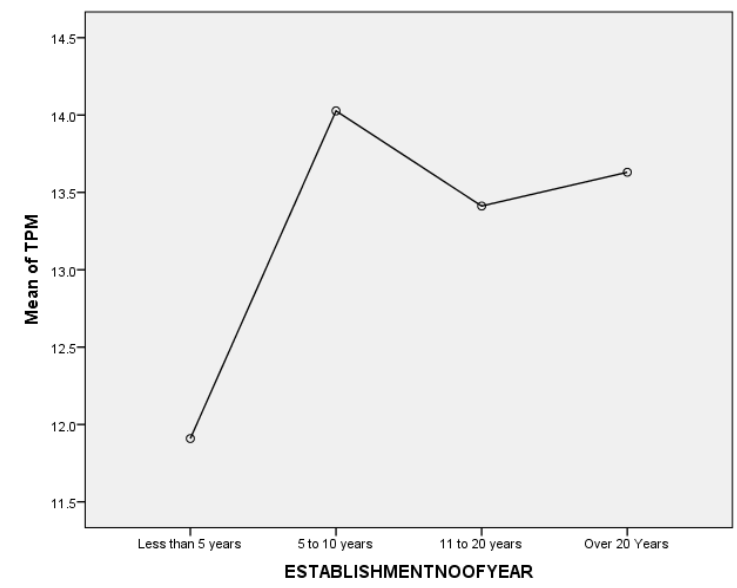

Figure 2: Mean Plot between TPM and Number of Years of Establishment.

The figure 2 above shows the variation in TPM scores according to number of years of establishment. The figure 2 depicts that TPM scores increases with the number of years of establishment. So it appears that as the number of years of establishment increases the application of TPM based lean practices in the industry is also increased.

\section{RESULT AND DISCUSSION}

The practical use of the lean practices (implementation of lean practices) is also affected by the number of years of establishment to the industries (age of the plant). The number of years of establishment to the industry is gauged on the basis of how many years since plant has been started. Data is collected on four pointer; 1 for Less than 5 years, 2 for 5-10 years, 3 for 11-20 years and 4 for more than 20 years. The relationship between the practical use of lean practices and the number of years of establishment to the industry is studied statistically through SPSS software. The relationship between 
four lean bundles (JIT, TPM, TQM and HRM) and number of years of establishment to the industry has been studied through the one way anova test. The results indicate that the number of years of establishment significantly influences TPM Only $(\mathrm{F}(3,124)=6.12, \mathrm{p}<.01)$. In this way it has been revealed from this study that implementation of practices from the TPM bundle gets affected by the number of years of establishment to the industry and it is also empirically established through this research study. Further from the analysis of the data, it has been revealed that the as the number of years of establishment increases the application of TPM based lean practices in the sample industries is also increased.

\section{FUTURE SCOPE}

The results and experience achieved in this research study indicates some recommendation for future research work in this direction. Since this study involves a relatively small sample size, a more comprehensive study with large sample size is needed in order to evaluate the effects of lean practices implementation. This study was carried out on the mainly central India based industries, therefore further research work would be needed to verify whether the results are the same in others region too.

\section{Conflict of Interest}

There is no conflict of interest among any one in this research study.

\section{REFERENCES}

1. Balaji M, Muniraju M, (2017), "Challenges In Implementation Of Lean Management In Indian MSMES - A Study", International Journal of Management Studies, 4 (1) Special Issue, pp1-10.

2. Bhadury, B. (2000). Management of productivity through TPM. Productivity, 41(2), 240-51.

3. M. Yogesh, G. Chandramohan \& P. R.Vishruth, "Innovations in Manufacturing Systems and Technologies for Global Competitiveness: A Context of Lean Manufacturing “, BEST: International Journal of Management, Information Technology and Engineering (BEST: IJMITE), Vol. 3, Issue 10, pp. 43-52

4. Cua, K. O., McKone, K. E., \& Schroeder, R. G. (2001). Relationships between implementation of TQM, JIT, and TPM and manufacturing performance. Journal of operations management, 19(6), 675-694.

5. Dal Pont, G., Furlan, A., \& Vinelli, A. (2008). Interrelationships among lean bundles and their effects on operational performance. Operations Management Research, 1(2), 150-158.

6. Fullerton, R. R., \& McWatters, C. S.(2001). The production performance benefits from JIT implementation. Journal of operations management, 19(1), 81-96.

7. Jadhav, J. R., Mantha, S. S., \& Rane, S. B. (2014). Development of framework for sustainable Lean implementation: an ISM approach. Journal of Industrial Engineering International, 10(3), 1-27.

8. Jadhav J. R, Mantha S. S, Rane S. B,(2015), "Roadmap for Lean implementation in Indian automotive component manufacturing industry: comparative study of UNIDO Model and ISM Mode”, Journal of Industrial Engineering International, 11(2), 179-198

9. Er. Amit B. Dutta \& Er. Sneha Banerjee, "Review of Lean Manufacturing Issues and Challenges in Manufacturing Process “, IMPACT: International Journal of Research in Business Management (IMPACT: IJRBM), Vol. 2, Issue 4, pp. 27-36

10. Leedy, P. N., \& Ormrod, J. E. (2010). Practical research. Upper Saddle River. NJ: Prentice Hall. 
11. Kumar, R , Kumar, V. (2016). Analysis of significant lean manufacturing elements through application of interpretive structural modeling approach in Indian industry.Uncertain Supply Chain Management, 4(1), 83-92.

12. Lyonnet, B., (2010). Improvement of industrial performance: towards a Lean production system tailored to companies. PhD thesis.

13. Moubray, J. (2003). 21st century maintenance organization part I: the asset management model. Maintenance Technology, 16(2), 25-32.

14. Pallant, J. (2005). SPSS survival manual: A step by step guide to data analysis using SPSS, Allen \& Unwin, NSW, Australia.

15. Panizzolo, R. (1998). Applying the lessons learned from 27 lean manufacturers: The relevance of relationships management. International journal of production economics, 55(3), 223-240.

16. Priya H and Saleeshya P.G, (2018), "Suitability and adaptability of Lean manufacturing in Indian pharmaceutical sector", The 3rd International Conference on Materials and Manufacturing Engineering, IOP Conference Series: Materials Science and Engineering, pp 390.

17. Komal Singh \& Akshay Deokar, "Effects of 5S Implementation on Performance of Organization”, International Journal of Business andGeneral Management (IJBGM), Vol. 7, Issue2,pp.1-14

18. Ramakrishnan V, Jayaprakash J, Elanchezhian C, Ramnath B.V, (2019), "Implementation of Lean Manufacturing in Indian SMEs- A case study”, Material today: proceedings 16(2), pp1244-1250

19. Saurin, T. A., \& Ferreira, C. F. (2008). Qualitative assessment of the implementation of lean production practices: a case study in a heavy machinery manufacturer. Gestão \& Produção, 15(3), 449-462.

20. Shah, R., \& Ward, P. T. (2003). Lean manufacturing: context, practice bundles, and performance. Journal of operations management, 21(2), 129-149.

21. Shah, R., \& Ward, P. T. (2007). Defining and developing measures of lean production. Journal of operations management, 25(4), 785-805.

22. Siemerink, M. G. J. (2014). The effects of lean management on organizational structure and the type of innovations influenced by this structure. Thesis, Faculty of Management and Governance, University of Twente, The Netherlands.

23. Singh, S., \& Garg, D. (2011). JIT system: concepts, benefits and motivation in Indian industries. International Journal of Management Business Study 1(1), 26-30.

24. Tortorella, G. L., Marodin, G. A., Miorando, R., \& Seidel, A. (2015). The impact of contextual variables on learning organization in firms that are implementing lean: a study in Southern Brazil. The International Journal of Advanced Manufacturing Technology, 78(9-12), 1879-1892.

25. Ul Hassan, M., Mukhtar, A., Qureshi, S. U., \& Sharif, S. (2012). Impact of TQM Practices on Firm's Performance of Pakistan's Manufacturing Organizations. International Journal of Academic Research in Business and Social Sciences, 2(10), 232.

26. R. Udhayakumar \& P. Karthikeyan, “Adoption of Last Planner System Using Engineer's Day-Wise Card in Civil Projects for Career Advancement “, BEST: International Journal of Management, Information Technology and Engineering (BEST: IJMITE), Vol. 3, Issue 9, pp. 69-76

27. Womack, J. P., \& Jones, D. T. (2010). Lean thinking: banish waste and create wealth in your corporation. Simon and Schuster. 


\section{APPENDIX 1: ACTUAL PART OF QUESTIONNAIRE}

\section{Section A: General Information}

1. Name of the company:

2. Job Designation of Respondent's: Which of the following best describe your current designation?

- Senior Engineer

- Manager

- Senior Manager

- Assistant General Manager

- $\quad$ Other (Please Specify).

3. Respondent`s Qualification: Please indicate your highest qualification:
1. Diploma in Engineering
2. Bachelor Degree in Engineering
3. Post Graduation in Engineering
4. Other

4. Respondent`s Experience: Please indicate your experience:
1. Less than 5 years
2. 5-10 years
3. 11-20 years
4. More than 25 years

5. Size of the Industry: How many employees are employed in your industry?
1. $0-150$
2. $151-300$
3. $301-450$
4. More than 450

6. Years of Establishment: How many years has it been since plant start-up?
1. Less than 5 years
2. 5-10 years
3. 11-20 years
4. More than 20 years

Section B: Level of Understanding and Practical use of the Lean Practices

Please tick $(\sqrt{ })$ as per your work experience:

\begin{tabular}{|c|l|c|c|c|c|c|c|}
\hline S. No. & \multicolumn{1}{|c|}{ Lean Tools } & $\begin{array}{c}\text { Lean } \\
\text { Bundle }\end{array}$ & $\begin{array}{c}\text { Never } \\
\text { Used 1 }\end{array}$ & $\begin{array}{c}\text { Rarely } \\
\text { Used 2 }\end{array}$ & $\begin{array}{c}\text { Partially } \\
\text { Used 3 }\end{array}$ & $\begin{array}{c}\text { Frequently } \\
\text { Used 4 }\end{array}$ & $\begin{array}{c}\text { Continuous } \\
\text { Used 5 }\end{array}$ \\
\hline B1 & Cellular Manufacturing & JIT & & & & & \\
\hline B2 & $\begin{array}{l}\text { Single Minute } \\
\text { Exchange of Dies }\end{array}$ & JIT & & & & & \\
\hline B3 & Pull System/Kanban & JIT & & & & & \\
\hline B4 & Small Lot Size & JIT & & & & & \\
\hline B5 & Line Balancing & JIT & & & & & \\
\hline
\end{tabular}




\begin{tabular}{|c|l|c|l|l|l|l|l|}
\hline B6 & ycle Time ReductionC & JIT & & & & & \\
\hline B7 & Value Stream Mapping & JIT & & & & & \\
\hline B8 & Bottleneck Removal & JIT & & & & & \\
\hline B9 & Standardised Work & JIT & & & & & \\
\hline B10 & Supplier Involvement & TQM & & & & & \\
\hline B11 & Customer Involvement & TQM & & & & & \\
\hline B12 & $\begin{array}{l}\text { On time deliveries to } \\
\text { customer }\end{array}$ & TQM & & & & & \\
\hline B13 & 5S & TQM & & & & & \\
\hline B14 & $\begin{array}{l}\text { Visual Management \& } \\
\text { Control }\end{array}$ & TQM & & & & & \\
\hline B15 & Continual Improvement & TQM & & & & & \\
\hline B16 & Poka Yoke & TQM & & & & & \\
\hline B17 & Benchmarking & TQM & & & & & \\
\hline B18 & Quality Circle & TQM & & & & & \\
\hline B19 & $\begin{array}{l}\text { Cross Functional } \\
\text { Teams }\end{array}$ & HRM & & & & & \\
\hline B20 & Takt Time Production & JIT & & & & & \\
\hline B21 & Multiskilled Employees & HRM & & & & & \\
\hline B22 & Employee Involvement & HRM & & & & \\
\hline B23 & $\begin{array}{l}\text { Overall Equipment } \\
\text { Effectiveness } \\
\text { Maintenance }\end{array}$ & TPM & & & & \\
\hline BPM & & & & \\
\hline Programs & & & & \\
\hline
\end{tabular}



